garin Manufacturers, published in The American Food Journal for June 1922, points out the deficiencies of the fat-soluble vitamin in butter fat in the case of rickets and shows that cod-liver oil contains fat-soluble vitamins in much higher concentration than they occur in butter fat. $\mathrm{He}$ also indicates recent researches in analytical methods which extend the hope that we may soon be able to identify the different bodies.

The Department of Agriculture has started a comprehensive research on cottonseed and the products therefrom, in coöperation with the Interstate Cottonseed Crushers' Association. Drs. Jamieson and Baughman of the Bureau of Chemistry have already published a method for the analysis of crude vegetable oils, giving the amount of absolute oil obtainable from any sample of crude by alkali refining. The published results show that in refining crude oils by alkali, only 95 to 96 per cent of the available refined oil is obtainable in factory operations with existing methods. Work is now being done to separate and identify the various impurities present in the crude oil and to determine their effect on losses and quality of the refined oil. The same writers have also published analyses of cottonseed and peanut oils prepared from authenticated seeds from many localities and pressed under known conditions in the laboratory. These results give us the variations in the chemical constants of these oils and are far more reliable than those commonly published in the literature. For a full statement of the work done by the Bureau of Chemistry, the reader is referred to a very able article by Dr. W. W. Skinner in the Chemical Age for June 1922.

Considerable work has been done toward more accurately describing the colors of vegetable oils. A progress report of the Committee on Color of Oil and Seed was presented before the June meeting of the American Oil Chemists' Society. The report showed a highly improved colorimeter recently brought out by the Eastman Kodak Co., which makes it easily possible to report on the color of oils in the terms of yellow, red, and neutral tint or darkness. It is also possible to obtain color matches impossible with previous methods.

The same report gave a description of the color analyzer just perfected by Keuffel \& Esser, whereby it is possible to obtain a spectrophotometric curve of any sample of oil, and from the curve to determine whether it has been put through various refining processes. It also shows the difference in color between different oils. The instrument, needless to say, adds greatly to the facilities for research.

The constant requirements in manufacture call for more exact chemical information and methods, and call for travel on a little explored field. In the analyses of the oils themselves, we can separate the various fatty acids of the mixed glycerides; but what do we know of the mixed glycerides themselves, and their structure? It is highly desirable that methods should be devised for separating the different glycerides, both for analytical information and the proper control of manufactured products. This is particularly true in the industries dependent on hydrogenation. We may know the proportion of different fatty acids present, but have little more information regarding the structure of the fat and its resultant properties, than we could obtain regarding the design of a building by studying the bricks and stones constituting its ruins.

In the operating of bleaching oil by fuller's earth, we know little regarding the properties of the color removed, or just what action the earth has on the oil. We do know that the earth apparently oxidizes and polymerizes a portion of the oil and removes the same in addition to the color, but why and how we know not.

In deodorizing the oil by steam, certain malodorous principles are distilled off. It is not improbable that these might be developed into desirable perfumes.
In the extraction of crude oil by pressure, about 15 per cent of the total remains behind in the press cake. We know that it can be removed by solvent extraction. It is simply a question of mechanical and chemical research to substitute solvent extraction processes for the clumsy hydraulic presses. Solvent extraction produces choice oils in the laboratory, and with suitable apparatus can do the same in the factory.

The factors involved in the rancidity of fats and best means for preservation are important subjects for research of great practical value.

Each of the separate problems mentioned above resolves itself into many minor ones, so it may safely be said that the field of research in the edible fat industry is still a large one and well worthy of cultivation.

\section{Solvent Extraction of Vegetable Oils}

\section{By C. F. Eddy}

Research Associate, Research laboratory of Applied Chemistry, MassachusetTs Institute of TechnologX, Cambridge, Mass.

$\mathrm{T}$ THF STRESS of war conditions gave the solvent extraction industry a big impetus, especially in Europe. ${ }^{1, *}$ The success obtained has helped to break down prejudice and has stimulated investigation and discussion.

The higher yields obtainable by solvent extraction are clearly shown in a table given by Shrader, ${ }^{2}$ and Pickard's report ${ }^{3}$ that in five normal years before the war a solvent extraction plant for flaxseed gave a net return of $\$ 1.50$ per ton of raw material more than for a similar pressing plant, shows that the advantage is not merely theoretical.

Thiele ${ }^{4}$ has recently pointed out another advantage of this higher extraction of oil. When the oil has developed an appreciable amount of free fatty acids, a very low oil meal will be free from objectionable rancidity. In

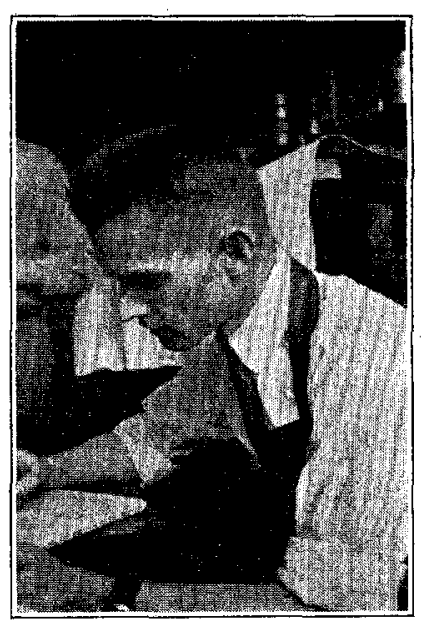

C. F. EDDY this connection, some have claimed that the steaming necessary to free the meal from solvent also increases its value for feed purposes.

Another advantage of the solvent extraction method that is being developed is in connection with the removal of free fatty acids from the extracted oil. In refining by the same method samples of pressed and solvent-extracted cottonseed oil, Shrader reports ${ }^{5}$ refining losses for the extracted oil much less than for the pressed oil. In a previous article $^{6}$ he refers to having tried Dr. Wesson's suggestion of refining the oil in solution instead of refining after the solvent had been removed. The only observation made was a comparison of the color of the oils refined by the two methods. If he was aware of the much greater simplicity of apparatus and method possible with refining in solution he did not mention it, and others have secured patents on the method. 7,8

The developments of processes and new types of apparatus $^{17-23}$ have been very numerous, but some of them, especially some unpublished ones, have been great improvements.

* Numbers in text refer to Bibliography at end of article. 